\title{
The NMR signature of gluconoylation: a frequent N-terminal modification of isotope-labeled proteins
}

\author{
David Schweida $^{1} \cdot$ Pierre Barraud $^{2,3} \cdot$ Christof Regl $^{1,4} \cdot$ Fionna E. Loughlin ${ }^{2,5} \cdot$ Christian G. Huber $^{1,4} \cdot$ Chiara Cabrele $^{1,4}$. \\ Mario Schubert ${ }^{1,2,4}$ (D)
}

Received: 22 December 2018 / Accepted: 24 January 2019 / Published online: 8 February 2019

(c) The Author(s) 2019

\begin{abstract}
$\mathrm{N}$-terminal gluconoylation is a moderately widespread modification in recombinant proteins expressed in Escherichia coli, in particular in proteins bearing an $\mathrm{N}$-terminal histidine-tag. This post-translational modification has been investigated mainly by mass spectrometry. Although its NMR signals must have been observed earlier in spectra of ${ }^{13} \mathrm{C} /{ }^{15} \mathrm{~N}$ labeled proteins, their chemical shifts were not yet reported. Here we present the complete ${ }^{1} \mathrm{H}$ and ${ }^{13} \mathrm{C}$ chemical shift assignment of the N-terminal gluconoyl post-translational modification, based on a selection of His-tagged protein constructs (CCL2, hnRNP A1 and Lin28) starting with Met-Gly-...-(His) $)_{6}$. In addition, we show that the modification can hydrolyze over time, resulting in a free $\mathrm{N}$-terminus and gluconate. This leads to the disappearance of the gluconoyl signals and the appearance of gluconate signals during the NMR measurements. The chemical shifts presented here can now be used as a reference for the identification of gluconoylation in recombinant proteins, in particular when isotopically labeled.
\end{abstract}

Keywords NMR spectroscopy · Post-translational protein modification · Gluconoylation · Gluconic acid · N-terminus · Recombinant protein $\cdot$ E. coli

Electronic supplementary material The online version of this article (https://doi.org/10.1007/s10858-019-00228-6) contains supplementary material, which is available to authorized users.

Mario Schubert

mario.schubert@sbg.ac.at

1 Department of Biosciences, University of Salzburg, Billrothstr. 11, 5020 Salzburg, Austria

2 Institute of Molecular Biology and Biophysics, ETH Zürich, 8093 Zurich, Switzerland

3 Institut de Biologie Physico-Chimique (IBPC), UMR 8261 CNRS, Université Paris Diderot, 13 rue Pierre et Marie Curie, 75005 Paris, France

4 Christian Doppler Laboratory for Innovative Tools for Biosimilar Characterization, University of Salzburg, Hellbrunnerstrasse 34, 5020 Salzburg, Austria

5 Department of Biochemistry \& Molecular Biology, Monash Biomedicine Discovery Institute, Monash University, Clayton, VIC 3800, Australia

\section{Introduction}

Post-translational protein modifications (PTMs) add another layer of complexity to the proteome and each modification can potentially change the structure, function and stability of a protein (Aebersold et al. 2018). For recombinant proteins, knowledge about the protein homogeneity and the presence of PTMs is crucial for most applications, e.g. pharmaceutical applications. N-terminal gluconoylation and phosphogluconoylation were first noticed by mass spectrometry in recombinant proteins expressed in Escherichia coli (Geoghegan et al. 1999; Yan et al. 1999a). The phosphogluconoyl moiety is formed by a spontaneous reaction of the metabolite 6-phosphogluconolactone with free N-termini of proteins (Fig. 1). The phosphate group is typically cleaved by host cell phosphatases leading to gluconoyl. The occurrence of these modifications depends on the $\mathrm{N}$-terminal sequence, and likely on the bacterial strain and the bacterial growth conditions. BL21(DE3), the most commonly used E. coli strain for protein expression, is known to accumulate 6-phosphogluconolactone due to the lack of 6-phosphogluconolactonase (Meier et al. 2012), which favors gluconoylation, so that it is not unexpected that this strain produces significant 
Fig. 1 Mechanism of gluconoylation according to Geoghegan et al. (1999), in which the metabolite 6-phospho-glucono-1,5-lactone, originating from glucose-6-phosphate, reacts spontaneously with a free $\mathrm{N}$-terminus of a protein

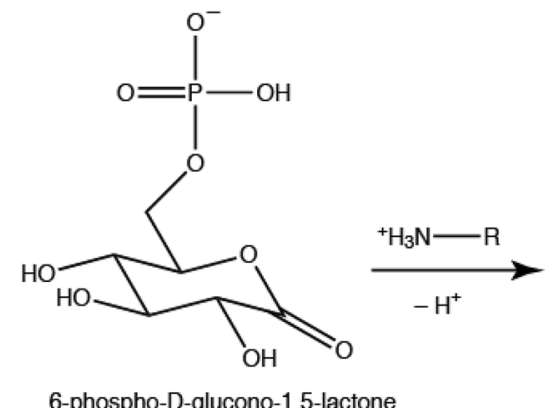

6-phospho-D-glucono-1,5-lactone<smiles>[2H]NC(=O)[C@H](O)[C@H](O)[C@H](O)[C@H](O)COP(=O)([O-])O</smiles>

N-terminal 6-phospho-D-gluconoyl modification<smiles>[R]NC(=O)[C@H](O)[C@@H](O)[C@H](O)[C@H](O)CO</smiles>

amounts of gluconoylated proteins. It was shown previously that gluconoylation occurs with many N-terminal histidinetagged proteins (Geoghegan et al. 1999; Yan et al. 1999a; Du et al. 2005; She et al. 2010; Martos-Maldonado et al. 2018) with $\mathrm{N}$-terminal sequences that are also found in widely used, commercially available expression vectors. However, one protein that did not contain an N-terminal histidine-tag was also reported to be highly susceptible to gluconoylation (Aon et al. 2008). The E. coli methionine aminopeptidase (MAP) is an essential enzyme involved in protein $\mathrm{N}$-terminal methionine excision. This enzyme is very well known for cleaving all proteins with small side chains on the residue directly following the N-terminal methionine (Flinta et al. 1986). For instance, proteins with Ala, Gly or Ser at the second amino-acid position are very efficiently processed by MAP (Frottin et al. 2006), and the gluconoyl group is thus attached to the second residue in that case (Yan et al. 1999b). Recombinant proteins expressed in M9 minimal medium seems to yield higher amounts of gluconoyl (Yan et al. 1999a) compared to Luria broth medium (Geoghegan et al. 1999; She et al. 2010), which is of special interest for the protein NMR community, because M9 minimal medium is routinely used for isotope labeling. Gluconoylation is highly selective for $\mathrm{N}$-termini, as shown by the treatment of model peptides and enhanced green fluorescent protein (EGFP) with gluconic acid $\delta$-lactone that led only to gluconoylation at the $\mathrm{N}$-terminus but not at the $\varepsilon$-amino group of Lys side chains (Martos-Maldonado et al. 2018).

Here we present the NMR chemical shifts of gluconoyl, which result in a characteristic signature in ${ }^{1} \mathrm{H}-{ }^{13} \mathrm{C}-\mathrm{HSQC}$ spectra, as illustrated by the spectra of Coprinopsis cinerea lectin 2 (CCL2) (Schubert et al. 2012), two domains of the RNA-binding protein hnRNP A1 (Barraud and Allain 2013) and the tandem zinc knuckles of pluripotency factor Lin28 (Loughlin et al. 2012). In addition, we observed that gluconoyl is cleaved over time at conditions like $\mathrm{pH} 5.8$ and $310 \mathrm{~K}$, which leads to the formation of gluconate and a free $\mathrm{N}$-terminus in longer NMR experiments. With the here presented chemical shift assignments, both $\mathrm{N}$-terminal gluconoyl and gluconate can be readily identified in NMR spectra.

\section{Materials and methods}

\section{Protein expression}

The lectin CCL2 was expressed using a pET22b vector as described earlier (Schubert et al. 2012). Either Luria broth (Thermo Fisher Scientific) or M9 minimal medium (Sambrook 2001) with or without ${ }^{13} \mathrm{C}$ and ${ }^{15} \mathrm{~N}$ isotope-labeling was used as culture medium. After affinity chromatography purification the buffer was exchanged to $50 \mathrm{mM} \mathrm{KK_{2 }} \mathrm{PO}_{4} /$ $\mathrm{K}_{2} \mathrm{HPO}_{4} \mathrm{pH} 5.8,150 \mathrm{mM} \mathrm{NaCl}$ by dialysis $(3.5 \mathrm{kDa}$ cutoff, Spectra/Por) and the proteins were concentrated with ultrafiltration devices (3 kDa cutoff, Amicon/Millipore or Vivaspin/Satorius). Most CCL2 spectra were recorded without ligand, but few were in complex with the trisaccharide GlcNAc $\beta 1,4[\mathrm{Fuc} \alpha 1,3] \mathrm{GlcNAc} \beta \mathrm{O}\left(\mathrm{CH}_{2}\right)_{5} \mathrm{COONa}$ at $\mathrm{pH} 4.7$. The individual domains of the RNA-binding protein hnRNP A1 were expressed and purified as described previously (Barraud and Allain 2013). Both domains were individually studied in complex with RNA, the RNA-recognition motif 1 (RRM1) in complex with the RNA UUAGGUC 
and RRM2 with the RNA UCAGUU in $10 \mathrm{mM} \mathrm{NaH}_{2} \mathrm{PO}_{4} /$ $\mathrm{Na}_{2} \mathrm{HPO}_{4}$ pH 6.5 as described earlier (Beusch et al. 2017). The tandem zinc-knuckles of Lin28 (amino acids 124-186) were expressed, purified and complexed with AGGAGAU RNA from pre-miRNA let-7 as described (Loughlin et al. 2012). Spectra of the Lin28-RNA complex were measured in $10 \mathrm{mM}$ sodium acetate $\mathrm{pH} 5.6,1.5 \mathrm{mM} \beta$-mercaptoethanol and $0.15 \mathrm{mM} \mathrm{ZnCl}_{2}$ at $303 \mathrm{~K}$.

\section{NMR spectroscopy}

All spectra were recorded on Bruker Avance III spectrometers operating at $500,600,750$ or $900 \mathrm{MHz}$, equipped with TCI, TXI or QXI probes at either $310 \mathrm{~K}$ or $303 \mathrm{~K}$. Standard 2D spectra like ${ }^{1} \mathrm{H}-{ }^{13} \mathrm{C}$ HSQC, ${ }^{1} \mathrm{H}_{-}{ }^{15} \mathrm{~N}$ HSQC were routinely measured. A 2D constant time ${ }^{1} \mathrm{H}-{ }^{13} \mathrm{C}$ HSQC was recorded with $26.6 \mathrm{~ms}$ (Vuister and Bax 1992). A 3D $\mathrm{HC}(\mathrm{C}) \mathrm{H}-\mathrm{COSY}$ (Gehring and Ekiel 1998) was recorded with $512 \times 37 \times 158$ complex points, $\mathrm{t}_{1 \max }=18.9 \mathrm{~ms}$, $\mathrm{t}_{2 \max }=2.79 \mathrm{~ms}$, eight transients. A 3D (H)CCH-TOCSY (Bax et al. 1990) was recorded with $512 \times 64 \times 54$ complex points, $\mathrm{t}_{1 \max }=5.1 \mathrm{~ms}, \mathrm{t}_{2 \max }=6.1 \mathrm{~ms}, 16$ transients and a mixing time of $23 \mathrm{~ms}$. Spectra were referenced to 2,2-dimethyl2-silapentanesulfonic acid (DSS) using an external sample of $0.5 \%$ DSS and $2 \mathrm{mM}$ sucrose in $\mathrm{H}_{2} \mathrm{O} / \mathrm{D}_{2} \mathrm{O}$ (Bruker), and indirect chemical shift referencing for ${ }^{13} \mathrm{C}$ and ${ }^{15} \mathrm{~N}$ according to IUPAB (Markley et al. 1998). Data was processed with Topspin 3.2 (Bruker, Germany) and analyzed with Sparky (T.D. Goddard and D.G. Kneller, SPARKY 3, University of California, San Francisco, USA).

\section{Mass spectrometry}

For analysis by mass spectrometry CCL2 samples without ${ }^{13} \mathrm{C}$ and ${ }^{15} \mathrm{~N}$ isotope-labeling were diluted to $1.0 \mu \mathrm{mol} \mathrm{L}{ }^{-1}$ in $\mathrm{H}_{2} \mathrm{O}+0.10 \%$ formic acid (FA, Sigma-Aldrich $\mathrm{GmbH}$, Steinheim, Germany). Ultrapure water was produced in house by a Milli-Q System (Millipore Corporation, Billerica, USA). Chromatographic separation of intact CCL2 proteins was carried out on an UltiMate 3000 Rapid Separation System (U3000 RSLC, Thermo Fisher Scientific, Germering, Germany) at a flow rate of $200 \mu \mathrm{L} \mathrm{min}^{-1}$ using a ProSwift RP10R column $(500 \times 1.0 \mathrm{~mm}$ i.d., Thermo Fisher Scientific, Sunnyvale, CA, USA), operated at a temperature of $70{ }^{\circ} \mathrm{C}$. Mobile phase A was $\mathrm{H}_{2} \mathrm{O}+0.10 \%$ FA, mobile phase $\mathrm{B}$ was composed of acetonitrile (VWR, Leuven, Belgium) $+0.10 \%$ FA. The gradient applied was: $20 \%$ B for $2 \mathrm{~min}, 20-50 \%$ B in $2 \mathrm{~min}, 80 \% \mathrm{~B}$ for $2 \mathrm{~min}$ and $20 \% \mathrm{~B}$ for $5 \mathrm{~min}$. Injection was carried out in in-line split-loop mode, injection volume was $10 \mu \mathrm{L}$ (1.0 pmol). UV-detection was carried out at $214 \mathrm{~nm}$ with a $2.5 \mu \mathrm{L}$ flow cell. Mass spectrometry was performed on a benchtop quadrupole-Orbitrap instrument (Q Exactive ${ }^{\mathrm{TM}}$ ) equipped with an Ion $\mathrm{Max}^{\mathrm{TM}}$ source with a heated electrospray ionization (HESI) probe, both from Thermo Fisher Scientific (Bremen, Germany). The instrument settings were as follows: spray voltage of $4.0 \mathrm{kV}$, sheath gas flow of 15 arbitrary units, auxiliary gas flow of 5 arbitrary units, capillary temperature of $275^{\circ} \mathrm{C}$, S-lens RF level of 60.0, AGC target of 5e6 and a maximum injection time of $200 \mathrm{~ms}$. The samples were analyzed with full scans at a scan range of $m / z, 800-2600$ and a resolution setting of 140,000 at $\mathrm{m} / \mathrm{z} 200$. The Xcalibur 3.0 software with the integrated Xtract algorithm was employed for deconvolution of raw mass spectra into zero charge-state spectra.

\section{Results}

\section{Chemical shift correlations of the gluconoyl group}

In NMR spectra of recombinant CCL2 in a ${ }^{13} \mathrm{C} /{ }^{15} \mathrm{~N}$ labeled form (Schubert et al. 2012) we observed quite intense and sharp ${ }^{1} \mathrm{H}-{ }^{13} \mathrm{C}$ chemical shift correlations with ${ }^{13} \mathrm{C}$ chemical shifts between 70 and 78 ppm (Fig. 2), and since it was not possible to get rid of those signals by changing the purification scheme, we considered that these signals arose from a post-translational modification. Mass spectra of unlabeled CCL2, expressed either in M9 minimal medium or LB medium, showed a signal at 16445.2 Da (Fig. 3) indicating the cleavage of Met1 and a signal corresponding to [M-Met1 + $178 \mathrm{Da}]$, which is indicative for gluconoylation (Geoghegan et al. 1999). However, to unambiguously confirm the presence of the gluconoyl group, we undertook a detailed NMR analysis.

${ }^{1} \mathrm{H}-{ }^{13} \mathrm{C}$ HSQC spectra of the recombinant lectin CCL2 (Schubert et al. 2012) showed the above mentioned sharp ${ }^{1} \mathrm{H}-{ }^{13} \mathrm{C}$ correlations (Fig. 2) in a region, where carbohydrate signals typically occur. The topology of the spin system could be studied by a 3D HC(C)H-COSY spectrum (Fig. 4a), whose analysis was, however, complicated by a second set of signals that appeared and turned out to be a hydrolysis product. Unfortunately, the two sets of signals partially overlapped (Fig. 2b). However, fresh samples contained only one set of signals (Fig. 2a), but two species were observed already after 2 days at $310 \mathrm{~K}$ (Fig. 2b). An aged sample that was used for several weeks of triple resonance experiments at $310 \mathrm{~K}$ showed only a single set of chemical shifts corresponding to the newly appeared signals. ${ }^{1} \mathrm{H}-{ }^{13} \mathrm{C}$ correlations in an edited ${ }^{1} \mathrm{H}-{ }^{13} \mathrm{C}$ HSQC revealed that the initial spin system consists of one $\mathrm{CH}_{2}$ and four $\mathrm{CH}$ groups (Fig. 2a). A constant-time ${ }^{1} \mathrm{H}-{ }^{13} \mathrm{C}$ HSQC, giving positive signals when an even number of ${ }^{13} \mathrm{C}$ neighbors is present and negative signals in case of an odd number of ${ }^{13} \mathrm{C}$ neighbors, revealed that most $\mathrm{CH}$ groups are part of a linear carbon chain (two ${ }^{13} \mathrm{C}$ neighbors), one terminal $\mathrm{CH}_{2}$ and one terminal $\mathrm{CH}$ resulting in a spin system $\mathrm{CH}-\mathrm{CH}-\mathrm{CH}-\mathrm{CH}-\mathrm{CH}_{2}$ (Fig. 4c), in 

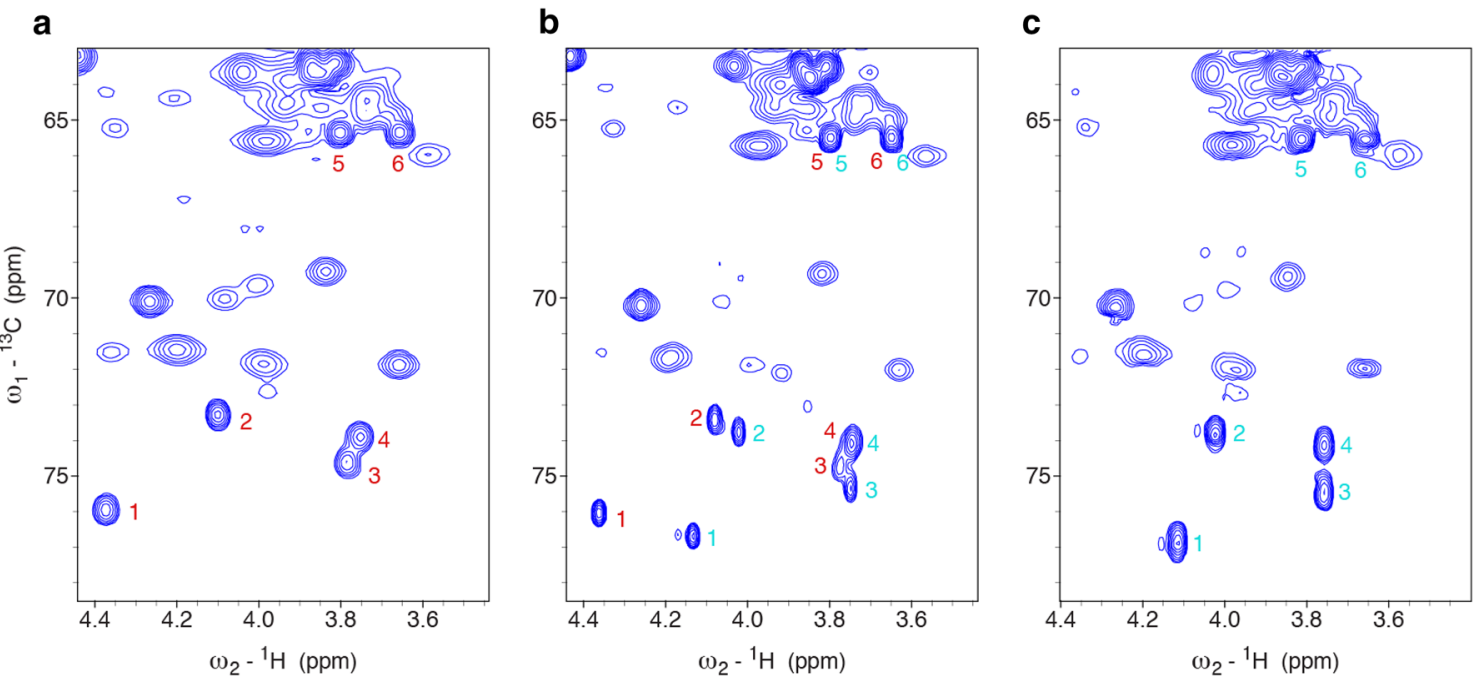

Fig. 2 Chemical shift correlations of the PTM observed in the lectin CCL2, illustrated with ${ }^{1} \mathrm{H}-{ }^{13} \mathrm{C}$ HSQC spectra, change with time. a Spectrum of a fresh ${ }^{13} \mathrm{C} /{ }^{15} \mathrm{~N}$ labeled sample recorded at $310 \mathrm{~K}$, pH 5.8 and $900 \mathrm{MHz}$. b Spectrum of a ${ }^{13} \mathrm{C} /{ }^{15} \mathrm{~N}$ labeled sample (in complex with carbohydrate ligand) after 5 days measurements at $310 \mathrm{~K}$, recorded at $310 \mathrm{~K}, \mathrm{pH} 4.7$ and $750 \mathrm{MHz}$. c Spectrum of a ${ }^{13} \mathrm{C} /{ }^{15} \mathrm{~N}$ labeled sample after 6 weeks triple resonance measurements, recorded at $310 \mathrm{~K}, \mathrm{pH} 5.8$ and $600 \mathrm{MHz}$
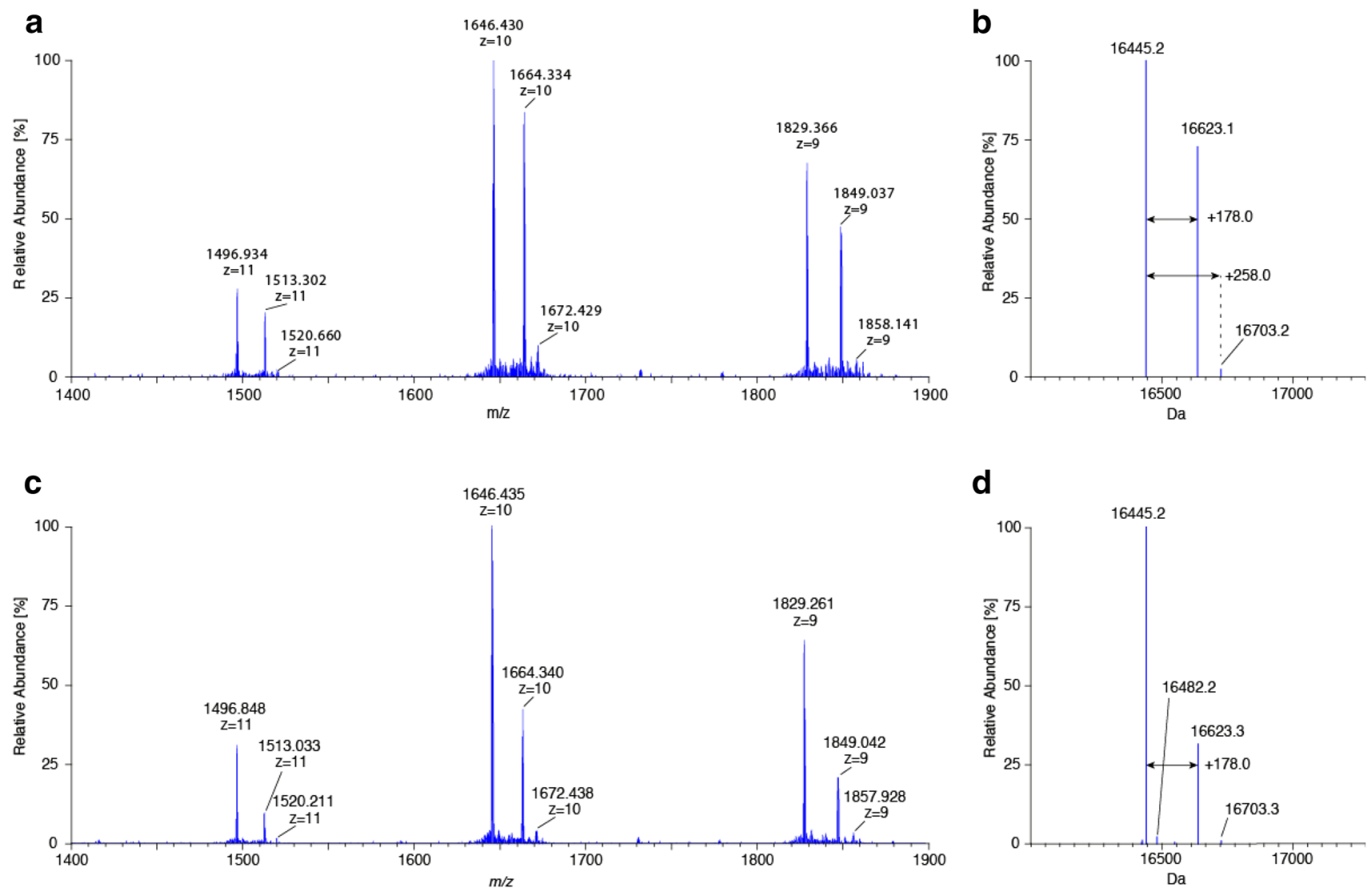

Fig. 3 Mass spectra of the recombinant lectin CCL2 at natural abundance. a Zoomed raw mass spectrum of +9 to +11 charge states of recombinant CCL2 expressed in M9 minimal medium. b Deconvoluted mass spectrum of CCL2 expressed in M9 minimal medium. c
Zoomed raw mass spectrum of +9 to +11 charge states of recombinant CCL2 expressed in LB medium. d Deconvoluted mass spectrum of CCL2 expressed in LB medium 

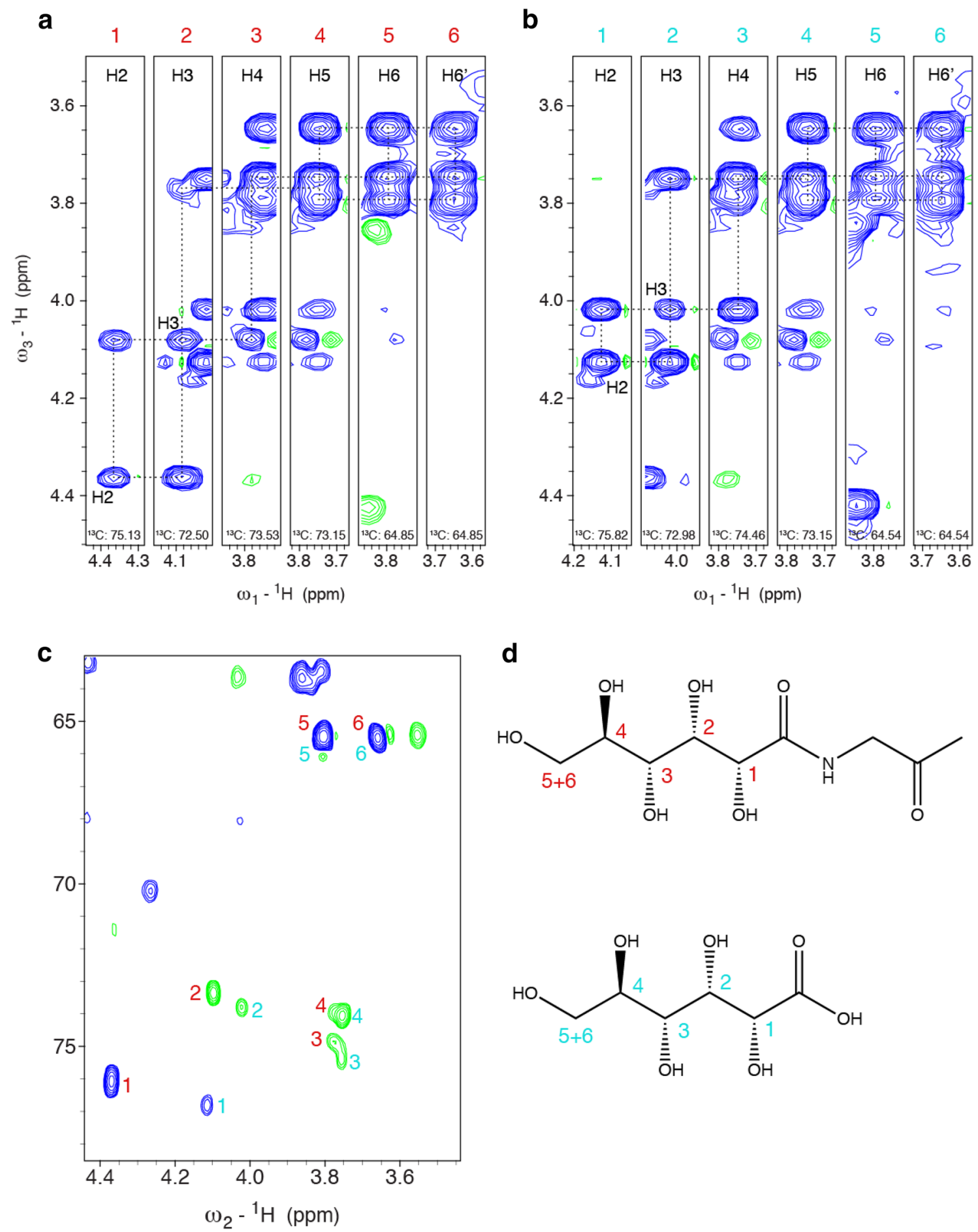

d<smiles>CC(=O)CNC(=O)[C@@H](O)[C@H](O)[C@H](O)[C@H](O)CO</smiles><smiles>O=C(O)[C@@H](O)[C@@H](O)[C@H](O)[C@H](O)CO</smiles>

Fig. 4 Three-dimensional $\mathrm{HC}(\mathrm{C}) \mathrm{H}-\mathrm{COSY}$ of a CCL2 sample containing both the initial gluconoyl set of signals and those of the hydrolysis product. a Strips showing the correlations of the gluconoyl spin system. Beside the positive signals in blue, few negative truncation artifacts of signals in other planes are visible in green. $\mathbf{b}$ Strips of the newly appearing spin system. The strips 4-6 are identical for both spin systems due to overlapping frequencies. c Constant-time ${ }^{1} \mathrm{H}-{ }^{13} \mathrm{C}$ HSQC recorded with constant time period of $26.6 \mathrm{~ms}$, resulting in

opposite signs for correlations of $\mathrm{CH}_{\mathrm{n}}$, depending on the number of ${ }^{13} \mathrm{C}$ neighbors. $\mathrm{A} \mathrm{CH}_{\mathrm{n}}$ group with one ${ }^{13} \mathrm{C}$ neighbor gives positive signals (blue), whereas one with two ${ }^{13} \mathrm{C}$ neighbors gives negative signals (green). The labels at the signals correspond to the labels of the strips in the 3D HC(C)H-COSY. d Chemical structures of the identified $\mathrm{N}$-terminal gluconoyl modification and its hydrolysis product gluconate. The labels of the observed signals are assigned to the corresponding atoms 
agreement with the topology of the gluconoyl carbon chain. Moreover, the obtained chemical shifts are comparable to those of gluconamide (Taravel and Pfannemuller 1990), $N$-octyl-gluconamide (Taravel and Pfannemuller 1990) and $\mathrm{N}$-hexyl-gluconamide (Carter et al. 2000) (Table 1). They also seem to fit with the signals of a gluconoylated unlabeled peptide, whose HSQC was recently published, unfortunately without mentioning the chemical shift values (Martos-Maldonado et al. 2018). In agreement with the mass spectra that only show traces of [M-Met1 +258 Da] (Fig. 3), we did not observe signals originating from 6-phosphogluconoyl moieties, indicating that the phosphate group was effectively cleaved after coupling of the 6-phosphogluconolactone to the protein $\mathrm{N}$-terminus (Fig. 1).

The second set of chemical shifts that appear over time was analyzed using $2 \mathrm{D}{ }^{13} \mathrm{C}-{ }^{1} \mathrm{H}$ correlations, 2D TOCSY and 3D HCCH-TOCSY spectra yielding also a spin system $\mathrm{CH}-\mathrm{CH}-\mathrm{CH}-\mathrm{CH}-\mathrm{CH}_{2}$. Inspired by the description of the hydrolysis of gluconamide to gluconate at elevated temperatures (Taravel and Pfannemuller 1990), we realized that the newly appearing signals show identical ${ }^{13} \mathrm{C}$ chemical shifts as gluconate (Table 1; Fig. 5). In addition, the observed ${ }^{1} \mathrm{H}$ chemical shifts match to previously reported ones for gluconate (Pallagi et al. 2010).

\section{Site and level of gluconoylation}

In a fresh sample of CCL2, a ${ }^{1} \mathrm{H}-{ }^{15} \mathrm{~N}$ correlation of Gly2 is visible in a ${ }^{1} \mathrm{H}^{15}{ }^{15} \mathrm{HSQC}$ spectrum (Fig. 6a), which however, disappears over time (Fig. 6b). In a 3D HNCA spectrum this amide correlates with two ${ }^{13} \mathrm{C}$ resonances at $45.0 \mathrm{ppm}$ and $44.0 \mathrm{ppm}$ (Fig. 6c), which correspond, to the $\mathrm{C} \alpha$ of Gly 2 and to a folded signal of $\mathrm{C} 2$ of the gluconoyl moiety (Fig. 6d) with a chemical shift of $76.1 \mathrm{ppm}$, respectively. This provides strong evidence that Met1 is absent and that the gluconoyl group is linked to Gly2.

Further, the ${ }^{15} \mathrm{~N}-{ }^{1} \mathrm{H}$ correlation of Gly 2 could be quantified. In a fresh protein preparation (Fig. 6a), the integral of the Gly2 signal showed volumes comparable to other amides, indicating nearly quantitative gluconoylation. However, after 1 week at $310 \mathrm{~K}$ the signal was completely lost (Fig. 6b). After hydrolysis, gluconate and a free $\mathrm{N}$-terminus are formed. The latter does not show any observable amide correlation because the $\mathrm{NH}_{3}^{+}$group exchanges rapidly with protons of water leading to the disappearance of the Gly2 signal.

The amount of gluconoylation was also analyzed by mass spectrometry of unlabeled CCL2 expressed in E. coli growing either on M9 minimal or LB medium (Fig. 3). The

Table 1 Comparison of the chemical shifts observed in this work (measured at $310 \mathrm{~K}$ ) and previously reported chemical shifts of gluconamides and gluconate (Taravel and Pfannemuller 1990; Carter et al. 2000; Pallagi et al. 2010)

\begin{tabular}{|c|c|c|c|c|c|c|c|}
\hline Nucleus & $\begin{array}{l}\text { Gluconoyl at } \\
310 \mathrm{~K} \text {, this } \\
\text { work }\end{array}$ & $\begin{array}{l}\text { Gluconamide } \\
\text { at } 303 \mathrm{~K}, \mathrm{D}_{2} \mathrm{O} \\
\text { reported by } \\
\text { Taravel and } \\
\text { Pfannemuller }\end{array}$ & $\begin{array}{l}N \text {-octyl- } \\
\text { D-gluconamide } \\
\text { at } 303 \mathrm{~K}, \mathrm{D}_{2} \mathrm{O} \\
\text { reported by } \\
\text { Taravel and } \\
\text { Pfannemuller }\end{array}$ & $\begin{array}{l}N \text {-hexyl-D-Glu- } \\
\text { conamide } 330 \mathrm{~K} \text {, } \\
\text { DMSO, by } \\
\text { Carter et al. }\end{array}$ & $\begin{array}{l}\text { Gluconate at } \\
310 \mathrm{~K} \text {, this } \\
\text { work }\end{array}$ & $\begin{array}{l}\text { Gluconate at } \\
303 \mathrm{~K} \text { reported } \\
\text { by Taravel and } \\
\text { Pfannemuller }^{\mathrm{a}}\end{array}$ & $\begin{array}{l}\text { Gluconate at } \\
298 \mathrm{~K}, \mathrm{pH} 6 \\
\text { reported by } \\
\text { Pallagi et al. }\end{array}$ \\
\hline $\mathrm{C} 1$ & 178.0 & 180.4 & 176.8 & 174.6 & n.d. & 181.4 & 181.5 \\
\hline $\mathrm{C} 2$ & 76.0 & 76.0 & 76.3 & 76.0 & 76.9 & 76.9 & 76.9 \\
\hline $\mathrm{H} 2$ & 4.37 & & & 4.23 & 4.11 & & 3.95 \\
\hline C3 & 73.3 & 73.1 & 73.2 & 72.4 & 73.9 & 73.8 & 73.8 \\
\hline H3 & 4.10 & & & 4.15 & 4.02 & & 4.03 \\
\hline $\mathrm{C} 4$ & 74.6 & 75.0 & 75.1 & 74.8 & 75.5 & 75.4 & 75.4 \\
\hline $\mathrm{H} 4$ & 3.79 & & & 3.75 & 3.76 & & 3.78 \\
\hline C5 & 73.9 & 73.9 & 74.0 & 73.8 & 74.1 & 74.0 & 74.1 \\
\hline H5 & 3.75 & & & 3.75 & 3.76 & & 3.74 \\
\hline C6 & 65.4 & 65.4 & 65.5 & 65.7 & 65.6 & 65.4 & 65.5 \\
\hline H6 & 3.81 & & & 3.83 & 3.81 & & 3.82 \\
\hline $\mathrm{H} 6^{\prime}$ & 3.66 & & & 3.64 & 3.66 & & 3.65 \\
\hline $\begin{array}{l}\mathrm{N} \text { (N-term. } \\
\text { glycine) }\end{array}$ & 109.9 & & - & - & - & - & - \\
\hline $\mathrm{HN}$ & 8.44 & & - & - & - & - & - \\
\hline
\end{tabular}

${ }^{\text {a }}{ }^{13} \mathrm{C}$ referencing was different, the values in this table correspond to the reported values $+3.0 \mathrm{ppm}$

b Personal communication by Dr. Donald Kiely, ${ }^{13} \mathrm{C}$ referencing was different, the values in this work correspond to the reported values $+2.2 \mathrm{ppm}$; also ${ }^{1} \mathrm{H}$ referencing was different, the values in this table correspond to the reported values $+0.25 \mathrm{ppm}$

${ }^{\mathrm{c}}{ }^{13} \mathrm{C}$ referencing was different, the values in this table correspond to the reported values $+3.1 \mathrm{ppm}$. Also ${ }^{1} \mathrm{H}$ referencing was different, the values in this work correspond to the reported values $+0.25 \mathrm{ppm}$ 
Fig. 5 Suggested reaction steps leading to the hydrolysis of gluconoylated protein chains<smiles>O=C(NP)[C@@H](O)[C@@H](O)[C@H](O)[C@H](O)CO</smiles><smiles>COC(O)(NCP)C(O)C(O)C(O)CO</smiles>
$\left.\uparrow\right|^{\text {temperature }}-\mathrm{NH}_{2} \mathrm{R}$<smiles>O=C(O)[C@@H](O)[C@@H](O)[C@H](O)[C@H](O)CO</smiles>
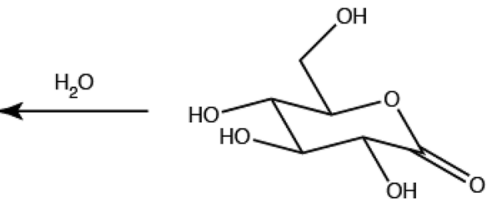

a

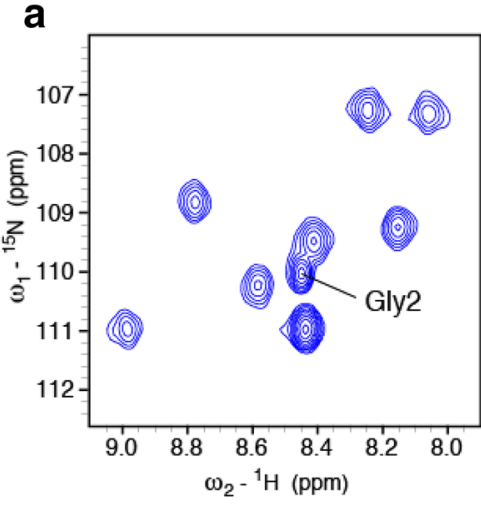

b

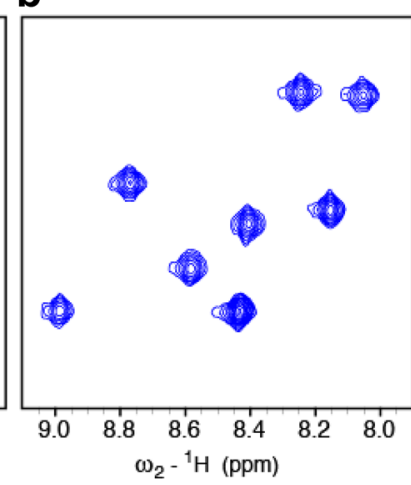

d

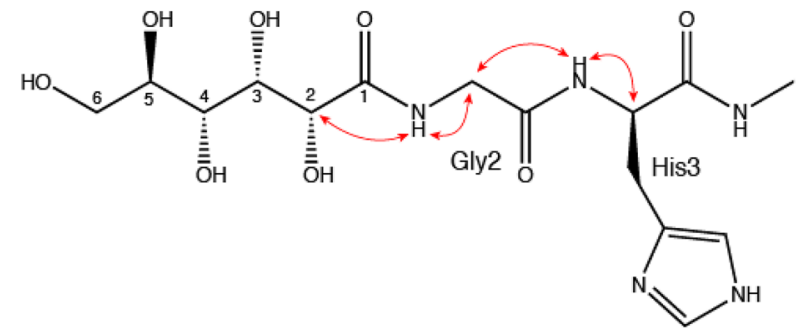

C

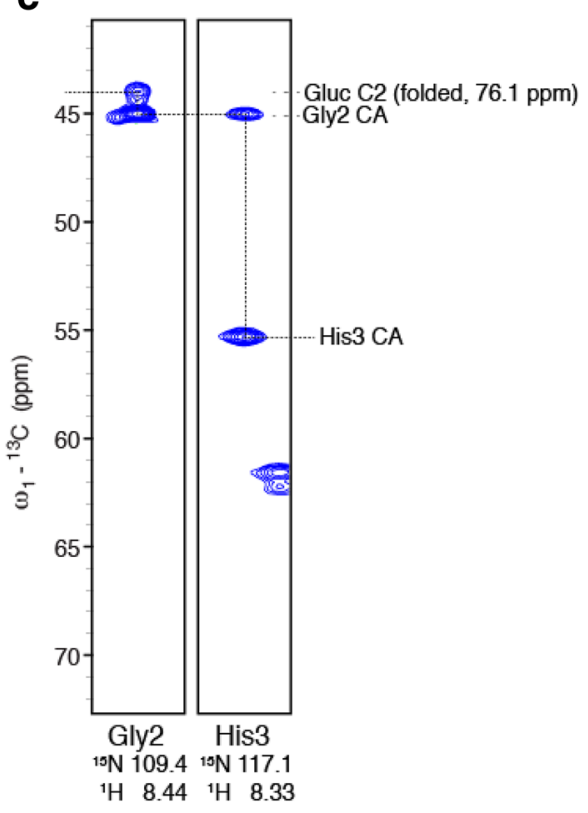

Fig. 6 Nearly quantitative gluconoylation in fresh CCL2 samples. a ${ }^{15} \mathrm{~N}-\mathrm{HSQC}$ of a fresh sample measured at $600 \mathrm{MHz}$ and $310 \mathrm{~K}$. The amide of Gly2 is indicated. b ${ }^{15} \mathrm{~N}-\mathrm{HSQC}$ of a sample after several weeks of measurement at $310 \mathrm{~K}$ at $900 \mathrm{MHz}$. c Strips of a 3D HNCA spectrum of a freshly prepared CCL2 sample (in complex with carbohydrate ligand). d Schematic illustration of the correlations observed in the 3D HNCA

with M9 minimal medium (Fig. 2), thus confirming the enhancement of gluconylation in M9 minimal media.

\section{Other examples of protein gluconoylation}

In addition to CCL2 we analyzed two domains of hnRNP A1 (Barraud and Allain 2013), and the tandem zinc knuckles (Supplementary Fig. S3) compared to the one prepared 
of pluripotency factor Lin28 (residues 124-186) (Loughlin et al. 2012), which were all recombinantly expressed in E. coli using ${ }^{13} \mathrm{C} /{ }^{15} \mathrm{~N}$ labeled $\mathrm{M} 9$ minimal medium. ${ }^{1} \mathrm{H}-{ }^{13} \mathrm{C}$ HSQC spectra of the two RRM domains of hnRNP A1 and also the Zn-knuckles of Lin28 (Supplementary Fig. S1) display exactly the same ${ }^{1} \mathrm{H}-{ }^{13} \mathrm{C}$ correlations as described for CCL2, confirming the presence of the gluconoyl modification. Similarly, after few days of incubation at $303 \mathrm{~K}$, the signals of the hydrolysis product gluconate appeared (Supplementary Fig. S1).

The gluconoyl chemical shifts of these examples (Supplementary Table S1) are almost identical to the ones observed for CCL2 (Table 1). To further verify if $\mathrm{pH}$ and temperature have an influence on the chemical shifts, we measured spectra of CCL2 at pH 7.5 and at the temperature of $298 \mathrm{~K}$ and 310 K (Supplementary Fig. S4). Highly similar chemical shifts were obtained (Supplementary Table S1).

\section{Discussion and conclusions}

The degree of gluconoylation of certain recombinant proteins expressed in $E$. coli depends on the type of medium. Expression in M9 minimal medium resulted in higher abundance of gluconoyl compared to the expression in LB medium, which is particularly important for the production of isotopically labeled proteins for NMR spectroscopy. One explanation might be that the high glucose concentration in the M9 minimal medium leads also to high glucose-6-phopsphate and, subsequently, to high 6-phosphogluconolactone concentrations, which is the metabolite that is able to react with the free $\mathrm{N}$-terminus of proteins. In addition, the cells are more stressed when growing in minimal medium.

Concerning the protein sequence preferences of gluconoylation, Geoghegan et al. reported that sequences starting with (M)GXXHHHH with XX being SS, SA, AS or AA, were all highly susceptible to gluconoylation (Geoghegan et al. 1999). The CCL2 construct started with (M)GHHHHHHHH, which was chosen to obtain high affinity for $\mathrm{Ni}$-NTA. However this tag seems to be extremely susceptible to gluconoylation, because we obtained nearly quantitative modification with a ${ }^{15} \mathrm{~N}$-labeled sample. Interestingly, a recent work aiming at the optimization of the $\mathrm{N}$-terminal acylation of proteins identified GHHHHHH as the sequence with the highest reactivity towards gluconolactone and full conversion in vitro (Martos-Maldonado et al. 2018). The RRM domains of hnRNP A1 and also the Zn-knuckles of Lin28, which all started with (M)GSSHHHH showed significant gluconoylation, in agreement with Geoghegan et al. Gluconoylation is a non-enzymatic reaction that seems to be catalyzed by imidazoles in the vicinity following a general base catalysis (Martos-Maldonado et al. 2018). The more His residues that follow the $\mathrm{N}$-terminus, the higher are the obtained gluconoyl yields. This might be explained by the fact that the $\mathrm{pK}_{\mathrm{a}}$ of His is decreased in poly-His stretches making it a better base catalyst (Watly et al. 2014). Having a Gly with a highly mobile backbone before a stretch of histidines seems to enhance gluconoylation, however, it was reported earlier that peptides starting directly with histidines are also highly reactive to gluconic acid $\delta$-lactone (MartosMaldonado et al. 2018).

The gluconoyl modification is not very stable, it slowly hydrolyzes, resulting in a free $\mathrm{N}$-terminus and gluconate. We observed hydrolysis at $\mathrm{pH}$ values 4.7-6.5 within few days and previous studies reported the hydrolysis of a gluconoylated peptide and a protein at $\mathrm{pH} 7.5$ over a period of 7 days (Martos-Maldonado et al. 2018). The hydrolysis pathway shown in Fig. 5 is, in principle, also a reaction in equilibrium, as the formed gluconolactone could potentially react again with a free $\mathrm{N}$-terminus to reintroduce the gluconoyl modification. However, the hydrolysis of the lactone to gluconate is not reversible. Moreover, we exclusively observed increasing amounts of gluconate, not of gluconolactone, in our NMR spectra with time.

The presented chemical shift assignments of the gluconoyl moiety, which were obtained for flexible $\mathrm{N}$-termini of folded proteins under slightly acidic conditions, will serve as a reference to unambiguously identify gluconoylation as PTM in any recombinant or isolated protein. In case of large proteins and severe line broadening, working under denaturing conditions might be an option. Several PTMs have been detected under such conditions with ${ }^{1} \mathrm{H}-{ }^{13} \mathrm{C}$ correlations (Schubert et al. 2015; Grassi et al. 2017; Peng et al. 2018). The chemical shifts of the hydrolysis product gluconate might slightly vary, because they depend on the $\mathrm{pH}$ and also on the presence of $\mathrm{Ca}^{2+}$ that can be chelated (Pallagi et al. 2010), but the gluconoyl chemical shifts should be widely independent of the $\mathrm{pH}$.

There are biotechnological activities that try to suppress gluconoylation. The widely used $E$. coli strain BL21(DE3) displays particularly high concentrations of $\delta$-6-phosphoand $\gamma$-6-phosphogluconolactone (Meier et al. 2012) compared to other strains like the K-12 MG1655. However, BL21(DE3) is highly optimized for recombinant protein expression, it has less active proteases and contains the T7 polymerase gene, which is required by many protein expression vectors. All these features make this strain an indispensible tool for the production of recombinant proteins. A possible solution to suppress gluconoylation while using BL21(DE3) cells relies on the overexpression of a heterologous phosphogluconolactonase that reduces the amount of active lactone and thus gluconoylation (Aon et al. 2008).

Acknowledgements Open access funding provided by Paris Lodron University of Salzburg. We like to thank Dr. Donald E. Kiely, University of Montana, for providing the chemical shifts of $N$-hexyl-D-gluconate that directed us to the right track. MS, PB and FEL gratefully acknowledge Prof. Frédéric Allain and the Biomolecular NMR Spectroscopy Platform at ETH Zürich at which some spectra were recorded. 
We thank Dr. Martin Wälti, Dr. Pascal Egloff, Dr. Silvia Bleuler Martinez and Dr. Markus Künzler, ETH Zürich, for the CCL2 plasmid and establishing an efficient purification protocol, Arthur Hinterholzer, University of Salzburg, for comments on the manuscript. The financial support by the Austrian Federal Ministry of Digital and Economic Affairs, the National Foundation for Research, Technology and Development and by a Start-up Grant of the State of Salzburg are gratefully acknowledged.

Author contributions MS designed the project and analyzed the data; PB and FEL provided data for hnRNP A1 and Lin 28 proteins; DS expressed and purified CCL2; CR and CGH measured and analyzed mass spectrometry data; MS recorded and analyzed NMR spectra; MS wrote the manuscript with input from PB, FEL, CR and CC; all authors discussed the results and approved the manuscript.

Funding The funding was provided by the Christian Doppler Forschungsgesellschaft [Christian Doppler Laboratory for Biosimilar Characterization].

\section{Compliance with ethical standards}

Conflict of interest The authors declare no conflict of interest.

Open Access This article is distributed under the terms of the Creative Commons Attribution 4.0 International License (http://creativeco mmons.org/licenses/by/4.0/), which permits unrestricted use, distribution, and reproduction in any medium, provided you give appropriate credit to the original author(s) and the source, provide a link to the Creative Commons license, and indicate if changes were made.

\section{References}

Aebersold R et al (2018) How many human proteoforms are there? Nat Chem Biol 14:206-214

Aon JC et al (2008) Suppressing posttranslational gluconoylation of heterologous proteins by metabolic engineering of Escherichia coli. Appl Environ Microbiol 74:950-958

Barraud P, Allain FHT (2013) Solution structure of the two RNA recognition motifs of hnRNP A1 using segmental isotope labeling: how the relative orientation between RRMs influences the nucleic acid binding topology. J Biomol NMR 55:119-138

Bax A, Clore GM, Gronenborn AM (1990) H-1-H-1 correlation via isotropic mixing of $\mathrm{C}-13$ magnetization, a new 3-dimensional approach for assigning $\mathrm{H}-1$ and $\mathrm{C}-13$ spectra of $\mathrm{C}-13$-enriched proteins. J Magn Reson 88:425-431

Beusch I, Barraud P, Moursy A, Clery A, Allain FHT (2017) Tandem hnRNP A1 RNA recognition motifs act in concert to repress the splicing of survival motor neuron exon 7. Elife 6:e25736

Carter A, Morton DW, Kiely DE (2000) Synthesis of some poly(4alkyl-4-azaheptamethylene-D-glucaramides). J Polym Sci A 38:3892-3899

Du P et al (2005) Phosphorylation of serine residues in histidine-tag sequences attached to recombinant protein kinases: a cause of heterogeneity in mass and complications in function. Protein Expr Purif 44:121-129

Flinta C, Persson B, Jornvall H, Vonheijne G (1986) Sequence determinants of cytosolic $\mathrm{N}$-terminal protein processing. Eur J Biochem 154:193-196

Frottin F et al (2006) The proteomics of N-terminal methionine cleavage. Mol Cell Proteom 5:2336-2349
Gehring K, Ekiel I (1998) H(C)CH-COSY and (H)CCH-COSY experiments for C-13-labeled proteins in $\mathrm{H}_{2} \mathrm{O}$ solution. J Magn Reson 135:185-193

Geoghegan KF et al (1999) Spontaneous alpha-N-6-phosphogluconoylation of a "His tag" in Escherichia coli: the cause of extra mass of 258 or $178 \mathrm{Da}$ in fusion proteins. Anal Biochem 267:169-184

Grassi L et al (2017) Complete NMR assignment of succinimide and its detection and quantification in peptides and intact proteins. Anal Chem 89:11962-11970

Loughlin FE et al (2012) Structural basis of pre-let-7 miRNA recognition by the zinc knuckles of pluripotency factor Lin28. Nat Struct Mol Biol 19:84-105

Markley JL et al (1998) Recommendations for the presentation of NMR structures of proteins and nucleic acids-IUPAC-IUBMB-IUPAB Inter-Union Task Group on the standardization of data bases of protein and nucleic acid structures determined by NMR spectroscopy. J Biomol NMR 12:1-23

Martos-Maldonado MC et al (2018) Selective N-terminal acylation of peptides and proteins with a Gly-His tag sequence. Nat Commun 9:3307

Meier S, Jensen PR, Duus JO (2012) Direct observation of metabolic differences in living Escherichia coli strains K-12 and BL21. ChemBioChem 13:308-310

Pallagi A et al (2010) Multinuclear NMR and molecular modelling investigations on the structure and equilibria of complexes that form in aqueous solutions of $\mathrm{Ca}(2+)$ and gluconate. Carbohydr Res 345:1856-1864

Peng JN, Patil SM, Keire DA, Chen K (2018) Chemical structure and composition of major glycans covalently linked to therapeutic monoclonal antibodies by middle-down nuclear magnetic resonance. Anal Chem 90:11016-11024

Sambrook J, Russell DW (eds) (2001) Molecular cloning: a laboratory manual, 3rd edn. Cold Spring Harbor Laboratory Press, Cold Spring Harbor

Schubert M et al (2012) Plasticity of the beta-trefoil protein fold in the recognition and control of invertebrate predators and parasites by a fungal defence system. PLoS Pathog 8:e1002706

Schubert M, Walczak MJ, Aebi M, Wider G (2015) Posttranslational Modifications of intact proteins detected by NMR spectroscopy: application to glycosylation. Angew Chem Int Ed 54:7096-7100

She YM et al (2010) Mass spectrometry following mild enzymatic digestion reveals phosphorylation of recombinant proteins in Escherichia coli through mechanisms involving direct nucleotide binding. J Proteome Res 9:3311-3318

Taravel FR, Pfannemuller B (1990) Amphiphilic properties of synthetic glycolipids based on amide linkages. 4. C-13 NMR spectroscopic studies on the gelation of N-octyl-D-gluconamide in aqueoussolution. Makromol Chem-Macromol Chem Phys 191:3097-3106

Vuister GW, Bax A (1992) Resolution enhancement and spectral editing of uniformly $\mathrm{C}$-13-enriched proteins by homonuclear broadband C-13 decoupling. J Magn Reson 98:428-435

Watly J et al (2014) Insight into the coordination and the binding sites of $\mathrm{Cu}^{2+}$ by the histidyl-6-tag using experimental and computational tools. Inorg Chem 53:6675-6683

Yan Z, Caldwell GW, McDonell PA (1999a) Identification of a gluconic acid derivative attached to the $\mathrm{N}$-terminus of histidinetagged proteins expressed in bacteria. Biochem Biophys Res Commun 262:793-800

Yan Z et al (1999b) Mass spectrometric determination of a novel modification of the N-terminus of histidine-tagged proteins expressed in bacteria. Biochem Biophys Res Commun 259:271-282

Publisher's Note Springer Nature remains neutral with regard to jurisdictional claims in published maps and institutional affiliations. 